The published research plans of the US Envirommental Protection Agency (EPA) and the US Energy Research and Development Administration (ERDA) have each been criticized by the Office of Technology Assessment for focusing largely on the development of technological "hardware" and giving little attention to socioeconomic research (broadly defined). This paper first examines socioeconomic research areas that EPA might be expected to cover, and shows that its plans for doing so are inadequate. The paper then identifies gaps in ERDA's coverage of socioeconomic research that remain unfilled even in the agency's updated plan. Several reasons for this neglect of socioeconomic research are hypothesized, namely: the dominance of research management by scientists and technologists; the apparent irrelevance and/or lack of success of socioeconomic research performed in the past; the greater political acceptability of technological compared with non-technological approaches to pollution control: the public's apparent faith in our ability to develop technological solutions to energy and environmental problems; and the compatibility of new technology development with economic growth. Following a discussion of these reasons, it is concluded that senior management positions in both agencies must no longer be monopolized by those with solely scientific and technical backgrounds; instead, managers should be appointed who not only have appropriate social science or professional qualifications but are also able to communicate to their colleagues, to lawmakers, and to the public at large, the importance of having a balanced research program with both technological and socioeconomic components. 


\section{the neglect of socioeconomic research by u.s. energy and environmental agencies}

by

W. David CONN

School of Architecture and Urban Planning, University of California, Los Angcles, California 90024, USA

\section{INTRODUCTION}

In June 1975, the US Energy Research and Development Administration (ERDA) submitted to Congress its first national plan for energy research, devclopment, and demonstration (RD \& D) [1], hereafter referred to by its document number, ERDA-48. Eight months later, in February 1976, the Office of Research and Development (ORD) of the US Environmental Protection Agency (EPA) submitted its first 5-year overview of ORD's research program, priorities, and trends [2]. By request of Congress, both documents were subjected to searching reviews by the Office of Technology Assessment (OTA) which published detailed critiques* [3, 4]. ERDA subsequently updated its original plan and the revised document [5], referred to as ERDA-76, was subjected to a comparative analysis by OTA, published in May 1976 [6] . A key issue in each of the OTA reviews has been whether the two agencies are paying sufficient attention to the need for socioeconomic** as opposed to purely technological research. ERDA-48, the EPA Research Outlook, and (to a lesser extent) ERDA-76 have all been criticized for giving only limited attention to socioeconomic research, but instead placing greatest emphasis on

* The present author was himself a participant in the OTA review of the EPA Research Outlook.

** It is important to clarify at the outset what is meant by "socioeconomic" research in this context, since there seems to be some confusion even among the writers of the plans and reviews. The term does not appear to be restricted to research in sociology and economics, but rather encompasses a broader range of disciplines and professions including political science, public administration, social psychology, law, management science, planning, etc.; in effect, it refers to all research other than that based on the physical, biological, and medical sciences. 
the use of technological "hardware" to solve energy and environmental problems. In this paper I shall discuss the need for socioeconomic research by the two agencies and comment on their response (or lack of response) to this need.

\section{RESEARCH BY THE ENVIRONMENTAL PROTECTION AGENCY}

Socioeconomic research needs

In the words of EPA's Assistant Administrator for Research and Development, the Agency's fundamental mission is "the achievement and enhancement of a quality environment" [7]. In support of this mission, EPA has "broad, essentially all-encompassing authorizations for research and developinent on the 'control, prevention, abatement, effects' of pollution' ([2], p. 10). Throughout the 5-year Research Outlook, there are repeated references to the need for socioeconomic research (in its broadest sense) to complement technical and scientific studies; however, neither the Outlook nor the testimony of EPA officials during the OTA review have provided any real evidence that a serious effort is being made to develop a substantial and coordinated program of socioeconomic research.

What areas might such a program encompass? At the very least, I would arguc that socioeconomic research is needed, in addition to technical studies, to assist in:

- Identifying present and future environmental problems, as well as opportunities for enhancement of the environment;

- Establishing appropriate goals and priorities;

- Developing alternative approaches to meeting these goals, giving due attention to the means of implementation; and

- Predicting the likely impacts of different approaches and evaluating the options.

These tasks are not necessarily sequential; on the contrary, since they are strongly inter-dependent, it is wise to have continual-feedback and iteration.

Without attempting to provide a complete list of topics that might be addressed in each area, a few illustrations can be given. In the first area (identifying problems and opportunities), there is a need for demographic forecasts and analyses of the population's likely activity patterns, spatial distribution, etc., on which to base predictions of environmental impacts. In the second area (establishing goals and priorities), it is important that goals be stated in specific enough terms so that measures can be developed to test for progression toward them or regression away from them. Some (though by no means 
all) goals are likely to be in the form of standards or desired levels of environmental quality, a few based on technical criteria alone (e.g., on an absence of identifiable health effects), but others requiring a balancing of different impacts; trade-offs must be made between competing national priorities such as economic well-being, energy self-sufficiency, and environmental protection. The costs and benefits of adopting different standards and levels need to be explored, requiring both the development of appropriate evaluative methodologies and their application.

In the third area (developing alternative approaches to meeting environmental goals), as the Outlook itself points out, it is important that non-technological, non-structural approaches receive attention as well as the technological methods that have been given highest priority in the past. Many of the latter are proving costly to implement and their effectiveness (especially in the long term) is occasionally open to doubt; for example, technologies that remove contaminants from waste streams do not generally provide complete solutions since they merely transfer the unwanted materials from one medium to another. Furthermore, the last traces of contaminants are generally very expensive or even impossible to remove by technological means; therefore, as waste streams increase in absolute quantities, relief from pollution is found to be only temporary (and the problem has now become more difficult to solve).

In some cases, attempting to influence, by non-technological means, the activity that creates a waste stream is likely to prove a more satisfactory and enduring solution than attempting simply to treat the stream technologically (although a combination of both approaches may prove best of all). For example, EPA itself has stated that in the long term, technological controls alone will not suffice in many air basins if the standards mandated in the Clean Air Act are to be met and maintained; land use and transportation controls requiring people to modify their behavior both in locating pollutiongenerating activities and in using polluting vehicles are considered essential. Research on the conception and development of these and other non-technological approaches is urgently required.

At the same time there is a need for research on the legal, institutional, and other considerations involved in implementing different measures, whether they be technological or non-technological in nature. New policy instruments need to be explored, for example, the use of economic incentives such as effluent charges (which, as distinguished from user fees, have not yet been employed in the US), and/or new regulatory procedures such as emission density zoning [8].

In the fourth of the areas listed above, there is a need to predict and evaluate 
the full range of impacts of both technological and non-technological control options, to assist decision-makers in choosing between them. Not only the financial costs of each option, but also the distributional effects, impacts on the social environment, effects on employment, etc., must be taken into account. Methodologies both for the prediction and the evaluation of many of these impacts are currently poorly developed: for example, even cost-benefit analysis (which is one of the more refined evaluative techniques) still suffers from many unresolved problems relating to the choice of objective function, the correct measure of costs and benefits, the evaluation of socalled "intangibles", the treatment of time, etc. Research is essential to further develop and then apply the methodologies deemed most appropriate. It is important to recognize that research is needed not only on the substance of environment policy issues, but also on the process of resolving these issues. For example, federal policy currently places great emphasis on the development of planning processes at the state or sub-state (regional or local) levels to achieve nationally established environmental quality goals, and assistance in the form of research and demonstration is required if these planning efforts are to succeed. The "lower" levels of government commonly lack both the technical expertise and the financial capability to carry out all of the necessary research by themselves; furthermore, if they attempt to do so, there is likely to be much duplication of efforts. The federal agency (i.e., EPA) has a clear responsibility to provide the appropriate research assistance.

\section{EPA's plans for socioeconomic research}

In the last section I identified several areas of socioeconomic research that EPA might reasonably be expected to address in carrying out its stated mission. Indeed, I would argue that these research areas are vital parts of a federal environmental program, and that EPA must address them (for no other agency is likely to do so). It is now appropriate to examine the Research Outlook to find out which, if any, of these areas ORD intends to cover.

At the outset there is a problem in that the Outlook is written in such a way as to make it difficult to determine precisely what ORD does plan to do and what funding will be available for given areas of research. In the Outlook as published, budget allocations are specified by broad program areas only, although an earlier unpublished draft which was seen by participants in the OTA review (and subsequently withdrawn by EPA) did give a slightly more detailed breakdown. It is especially difficult to isolate funds intended for projects in socioeconomic research since these are not confined to a single program area but instead are scattered among various different programs. This 
fragmentation of socioeconomic research is itself thought to pose a major organizational problem, as the result of which the OTA review calls for "a coherent and consistent organizational structure . . . to correct deficiencies in research policy, planning, management, coordination, and utilization of socioeconomic research" ([14], p.91). Careful scrutiny of the Outlook in fact reveals only two places where socioeconomic research seems to figure significantly, although there are numerous other places where it receives a brief mention.

The Environmental Management Subprogram (within the Public Sector Activities Program) specifically addresses the problems of planning at state or regional levels, having as its goal that of giving "regional environmental planners and managers methods to determine feasible alternative solutions to specific environmental problems and provide techniques to select least-cost solutions" ([2], p. 97). However, as pointed out in the OTA review, the program seems grossly underbudgeted (it will apparently receive some $2-3$ million dollars per year compared with the billions of dollars allocated to physical construction programs) and there is no evidence that ORD's management view it as a major priority.

Within the Health and Ecological Effects Program, there is a section entitled "Socioeconomic Studies" which would seem to be the place where more of the research needs identified earlier might be met. A list of topics is given which includes "benefit studies", "conservation issues", "waste reduction", and "methods and model development" ([2], pp. 63-64). However, these are simply the "likely candidates from which the five-year program will be assembled"; virtually no details are given and there is no indication of priorities, level of funding, etc. By claiming that the "groups doing this work will be assembled in FY 1976 and be at full or nearly full strength by the beginning of FY 1977" the Outlook seems to confirm what has been heard informally from other sources, namely that ORD currently lacks qualified personnel to plan and perform research in this area, and that a viable program does not yet exist. Furthermore, at the time of the OTA review (February 1976), it appeared that little or no progress had been made toward remedying this situation, which is more evidence of the low priority and interest afforded socioeconomic research by ORD management.

As stated earlier, there are numerous brief mentions of socioeconomic research needs scattered elsewhere throughout the EPA plan; yet, as the OTA review points out, "so little follows in the way of reasoned proposals and structured programs as to cast serious doubt on ORD's commitment to research in this area" ([4], p. 91). 


\section{RESEARCH BY THE ENERGY RESEARCH AND DEVELOPMENT AD- MINISTRATION}

Whereas EPA's activities are complicated by the need to carry out both regulatory and research functions, ERDA has a single mandate: it is to assume the leadership responsibility in energy RD \& D, including responsibility for developing and updating the National Plan for energy RD \& D. As mentioned at the start of this paper, ERDA's original plan (ERDA-48) was issued in 1975, and an up-dated version (ERDA-76) appeared in the following year. In OTA's review of the original plan, ERDA was sharply criticized for the fact that "only limited attention (was) given to socioeconomic research and analysis in addressing the Nation's energy problems" ([3], p. 3). According to OTA's comparative review of the up-dated plan, ERDA has since made "significant progress" in dealing with this problem, with "efforts to incorporate socioeconomic analysis (being) described in each program area" ([6], pp. 1-2).

However, the evidence is not always convincing that the importance of this analysis is truly appreciated and that the agency is intending to devote adequate resources to specific projects in socioeconomic research. As examples of the problems that remain, I shall briefly discuss ERDA's research activities (or lack thereof) in three areas, namely:

- Conservation,

-- Implementation tools, and

- Evaluation methodology.

A key criticism of ERDA 48 related to its treatment of conservation. The plan gave a great deal of attention to the development of technological options for increasing the supply of energy through (for example) enhanced oil and gas recovery, the development of synthetic fuels from coal, the development of nuclear, solar, and geothermal energy sources, etc. However, the plan was criticized by OTA for giving very little attention to the alternative approach of examining the demand for energy and developing conservation strategies to improve utilization, thereby reducing the need for supply. The response in ERDA-76 has been to "single out" conservation technologies for increased attention. Nevertheless, two important problems remain. The first is that, despite the extensive discussion in the up-dated plan, the funding allocation for conservation research is (as the OTA comparative review points out) still only a very small proportion of ERDA's total budget; it amounts to some $3.8 \%$ of the total FY 77 budget and even this figure includes some items that OTA does not feel should come under the conservation heading.

The second problem is that ERDA's view of conservation is technologically oriented; the emphasis is almost entirely on improving energy efficiency by 
technological means, for example, by designing automobiles and appliances that consume less energy for a given level of output. There is no provision in the plan for research into non-technological means of conservation, such as research on alternative land-use patterns that might lead to less energyintensive life-styles. As an international comparative study has shown, the fact that per capita energy use in Sweden is much lower than in the US is partially due to the higher residential densities found in Sweden: “. . . apartment living is more common, potentially effecting energy savings through fewer external walls, better insulation, and more efficient heating systems. Shopping also oecomes easier, with more neighborhood stores; trips are shorter, often on foot; and smaller storage facilities are required, resulting in smaller refrigerators with consequent electricity savings" ([9], pp.1011-1012). Of course, simply establishing the technical feasibility of energy options, whether they be for increasing supply or reducing demand, is not sufficient; attention must also be paid to implementation. For example, international studies (such as the one cited above) have suggested that while higher prices partly account for the greater efficiency of energy utilization in European countries such as Sweden and West Germany, institutional and social factors are also crucial [9-12]. There have been, and still are many barriers to efficient energy use in the US: consumers have until recently had virtually no information about the energy consumption of the products they purchased; advertising and marketing practices have tended to place the greatest emphasis on initial costs rather than life-cycle costs; loan-granting policies and building codes have discouraged developers from spending more on better insulation, improved construction quality, etc. There is a role for government policy in removing some of these barriers and taking positive action to implement the more promising energy options, but before proceeding, it is important that research is done to provide the basis for developing the most effective policy-instruments and to identify likely problems in advance. For example, if a tax on fuels is planned as a means of raising energy prices [13], a detailed examination of the distributional implications should be carried out beforehand so that steps can be taken, if necessary, to mitigate the potential adverse impact on low income groups. If measures are to be taken to promote public transportation (the greater use of which is another factor contributing to the lower per capita energy consumption in Europe), then research should be conducted on ways of changing the attitudes of the majority of the US population who have so far shown thernselves to be very firmly attached to their automobiles.

ERDA's original plan was sharply criticized in the OTA review for not paying sufficient attention to problems of implementation, especially to the non- 
technical (e.g., social and institutional) constraints. ERDA-76 devotes somewhat more discussion to this subject-area but, as the OTA comparative review points out, there is little evidence of much growth in real projects. More substantive research is needed.

Another OTA criticism of ERDA 48 was its failure to provide for adequate research on the means of evaluating energy options. The problem of making tradeoffs between (for example) conflicting energy and environmental goals is an extraordinarily difficult one, and yet it received little attention. The development of techniques such as cost-benefit analysis and net energy analysis which can aid decision-makers in selccting between options was neglected in the original plan. ERDA-76 gives more attention to these research needs although, as OTA's comparative review points out, it provides more of a statement of "intent" than a developed research plan. Although there is much discussion of a new planning system - the Planning, Programming, Budgeting, and Review (PPBR) system - within ERDA itself, and of the importance of making tradeoffs between energy, economic, environmental and other factors in evaluating technological options, there is no clear indication that research on the methodologies involved will actually be carried out.

\section{SUGGESTED REASONS FOR THE NEGLECT OF SOCIOECONOMIC RESEARCH}

Although ERDA-76 represents a definite improvement over the agency's original plan in respect of its treatment of socioeconomic research, I still believe that neither the EPA nor ERDA give this research the priority it deserves. The budgets of both agencies are overwhelmingly biased in favor of support for research on technological "hardware". Several possible explanations can be hypothesized, namely:

- The dominance of research management by scientists and technologists;

- The apparent "irrelevance" and/or lack of success of socioeconomic research performed in the past;

- The greater political acceptability of technological compared with nontechnological approaches to pollution control;

- The public's apparent faith in our ability to develop technological solutions to energy and environment problems; and

- The compatibility of new technology development with economic growth. In both EPA and ERDA, the senior personnel responsible for research management are predominantly scientists or technologists. EPA's Office of Research and Development, for example, is headed by an Assistant Administrator who 
is a physicist; all four Deputy Assistant Administrators have science or medical degrees; and the fifteen laboratories are all headed by Directors who are similarly qualified.

Many of ERDA's management previously held positions in the Atomic Energy Commission and most (if not all) have technical qualifications. It seems inevitable that in seeking solutions to problems, these people will turn first to science and technology. They are less likely to appreciate the potential contribution of socioeconomic research.

During the OTA review of EPA's Research Outlook, one of the agency's senior managers commented that socioeconomic research is not given high priority because it has been largely irrelevant and unsuccessful in the past. While it is undeniably true that not all research in the socioeconomic area has been of uniformly high quality (any more than it has been in other areas), several factors should be taken into account in considering this statement. The first is that opinions can differ on relevancy. As mentioned above, most of ORD's management have technical degrees, and they may not always be the best judges of which socioeconomic research is most relevant. For example, it is no more reasonable to expect them to appreciate the importance of basic research projects in welfare economics (that may be needed to lay the foundation for the development of applied evaluative methodologies) than it is to expect non-scientists to recognize the significance of research on "halogenerated organics formation mechanisms" (part of the work on organic contamination of drinking water).

The choice of an appropriate criterion for success is a second factor. Socioeconomic research differs from technological research in that the former may have an explicitly normative content; thus there may be no intrinsically "correct" or "incorrect" solution to a given problem, but merely a suggested course of action based on a reading of people's values. While the success of a technological project can generally be judged fairly readily (c.g., by examining whether the product adequately performs a specified function), the success of a socioeconomic research study may be much more difficult to assess. A third factor is the past failure of the government to ensure development of the capability to adequately perform relevant socioeconomic research. Because of the good image of technological research, the government has invested huge resources in (for example) the fields of defense and space exploration. Large research units have been established, staffed by large numbers of technologically qualified researchers. Judged by their ability to deliver prespecified technological products, they have achieved many notable successes. In contrast, very few socioeconomic research units have been established with a test of relevancy applied to their work; instead, most socioeconomic re- 
search studies have been performed in academic institutions, where their success has been judged largely by peer review (e.g., by having the results accepted for publication in refereed journals). This procedure does not nomally provide an incentive to ensure relevancy, and therefore the capability for performing relevant socioeconomic research has not developed.

Taking these factors into account, it is not surprising that past socioeconomic research efforts have been subject to criticism. However, this does not mean that future efforts should cease; on the contrary, I would argue that the necessary capability should be developed, and the quality of the research improved. As I have attempted to show in this paper, there are important needs to be met.

The three remaining reasons that I have proposed above as possible explanations for the pre-occupation of EPA and ERDA with technological research reflect more general societal considerations. The first stents from the fact that technological solutions to problems seem very often to be more politically acceptable than non-technological solutions. For example, in tackling the air pollution problem, the public generally seem to prefer that vehicle manufacturers be required to install technological devices to reduce emissions from automobiles than that they themselves be required to change their driving habits to reduce the number of miles travelled. Both approaches create undesirable effects, but these effects are perceived differently: in the former case, they are indirect, appearing as higher automobile prices (and possibly changed operating costs), whereas in the latter case they are direct, appearing as "government interference" in the determination of lifestyles (apparently viewed by many as a much greater cost)*.

Thus, there has been much more resistance on principle in the US to the introduction of non-technological controls on vehicular use (such as parking surcharges, the exclusion of all but buses and car-pools from freeway lanes, etc.) than there has been to the requirement for increasingly stringent technological controls on automobiles, regardless of which measures cost the least in monetary terms. Similarly, in the energy field, the public in general seem to prefer that the government develop new technological means of increasing energy supply (even if this can be achieved only at considerable expense) than that they be required to cut down on energy use.

Not only do the public apparently prefer technological solutions, they also seem to have a deep-rooted faith that such solutions can always be developed.

* Of course, in practice, both approaches may ulimately have a similar erect, in that higher automobile prices may cause a reduction in the sale of autonobiles and this may in turn cause a reduction in the number of miles travelled. 
This faith is presumably based on the spectacular success that technology has had in solving certain types of problems in the past (like sending a man to the moon); people do not realize (or do not wish to realize) that not all problems are amenable to the same kind of treatment. As I mentioned earlier (when discussing EPA's research needs), technological approaches can have serious limitations; rather than providing complete solutions, they may simply transform the problems, and unless the technologies are 100\% effective, these problems may continue to increase in the long run.

Finally, it is highly significant that the development and introduction of new technological solutions to energy and environmental problems can contribute to economic prosperity as measured by conventional indicators (such as GNP) even though it may be "anti-bads" that are being produced rather than "goods". The manufacture of pollution control technology, for example, has given rise to a major growth industry. As the Sixth Annual Report of the President's Council on Environmental Quality points out, environmental programs have probably led to a net increase in the number of available jobs; they are not significantly disrupting capital markets or displacing significant amounts of investment for capital expansion; they are having only a small effect on the rate of inflation; and they are not having an identifiable adverse impact on foreign trade ([14], pp. 533-543). On the other hand, non-technological approaches that might, for example, deliberately set out to reduce the demand for certain (pollution-creating) goods could by their very success have a significant negative economic impact as conventionally measured. Until an indicator is developed which truly reflects the "quality of life" (which current economic indicators most certainly do not), economic accounting will almost always favor technological over non-technologial approaches.

\section{CONCLUSIONS}

In my opinion (and in the opinion of certain others involved in the OTA reviews), both EPA and (to a slightly less extent) ERDA are guilty of making inadequate provisions for needed socioeconomic research, but are instead concentrating their efforts largely on the development of technological hardware. I have suggested a number of reasons that might explain this situation. In terms of possible remedies, I feel that it is essential to alert those directing research in both agencies to the need for, and potential contribution of, well performed socioeconomic studies. For example, they must be made to realize that there is little point in developing a particular technology (no matter how successfully from a technical viewpoint) if socioeconomic research would 
show that this technology could not be implemented for institutional or other reasons. Alternatively, a non-technological approach might be shown to be more socially desirable.

It seems likely that this awareness will only come when senior management positions are no longer monopolized by those with solely scientific and technical degrees. What are needed are people who not only have appropriate social science or professional qualifications, but are also able to communicate the importance of socioeconomic research to others. As well as their colleagues within the agencies, they must be able to convince lawmakers and the public at large that technology alone is not sufficient to solve our energy and environmental problems. A balanced program of research, with both technological and socioeconomic components, is essential to provide the basis from which these problems may be addressed.

\section{ACKNOWLEDGEMENTS}

Donald M. McAllister and Walter E. Westman kindly provided comments on an earlier draft of this paper.

\section{REFERENCES}

[1] US Energy Research and Development Administration, A National Plan for Energy Research, Development and Demonstration: Creating Energy Choices for the Future, ERDA 48 , Vols. I and II (US Government Printing Office, Washington, 1975).

[2] Office of Research and Development, Environmental Research Outlook FY 1976 through 1980, Report to Congress, EPA-600/9-76-003 (US Environmental Protection Agency, Washington, 1976)

[3] United States Congress, Office of Technology Assessment, An Analysis of the ERDA Plan and Program (US Government Printing Office, Washington, 1975).

[4] United States Congress, Office of Technology Assessment, $A$ Review of the US Environmental Protection Agency Environmental Research Outlook $F Y 1976$ through 1980 (US Government Printing Office, Washington, 1976).

[5] US Energy Research and Development Administration, A National Plan for Energy Research, Development, and Demonstration: Creating Energy Choices for the future, ERDA-76, Vols. I and II (US Government Printing Office, Washington, 1976).

[6] United States Congress, Office of Technology Assessment, Comparative Analysis of the 1976 ERDA Plan and Program (US Government Printing Office, Washington, 1976).

[7] W. K. Talley, The Research Mission, EPA Journal 1 (1975).

[8] J. J. Roberts, E. J. Croke and S. Booras, A Critical Review of the Effects of Air Pollution Control Regulations on Land Use Planning, Journal of the Air Pollution 
Control Association 25 (1975) 500.

[9] L. Schipper and A. J. Lichtenberg, Efficient Energy Use and Well-Being: The Swedish Example, Science 194 (1976) 1001.

[10] L. Schipper, Raising the Productivity of Energy Utilization, in J. K. Hollander and M. K. Simmons, Annual Reliew of Energy, Volume 1 (Annual Reviews Inc., Palo Altu, 1976).

[11] R. Goen and R. White, Comparison of Energy Consumption Between West Germany and the United States (US Government Printing Office, Washington, 1975).

[12] P. P. Craig, J. Darmstadter and S. Rattien, Social and Institutional Factors in Energy Conservation, in J. K. Hollander and M. K. Simmons, Annual Review of Energy, Volume 1 (Annual Reviews Ine., Palo Alto, 1976).

[13] B. Hannon, Energy Conservation and the Consumer, Science 189 (1975) 95.

[14] Executive Otfice of the President, Council on Environmental Quality, Environmental Quality - The Sixth Annual Report of the Council on Environmental Quality (US Government Printing Office, Washington, 1975). 